\title{
Study of Stability of Saturated Salt Solutions Cells
}

\author{
Essam Eldin Mahmoud \\ National Institute for Standards, Tersa St. P. O. Box: 136 Giza, Code. No. 12211, El-Haram, Egypt
}

\begin{abstract}
This paper study stability of saturated salt solutions cells at $25^{\circ} \mathrm{C}$. These cells were prepared and measured at National Institute for Standard (NIS-Egypt) to study the stability of the saturated salt solutions. The study was carried out using three saturated salt solutions, which are Potassium Acetate 22.5\%, Potassium Iodide 68.9\% and Potassium Sulphate 97.3\% to cover low, medium and high relative humidity. The study was carried out using different shapes and volumes half liter spherical, liter spherical and liter conical per each salt which was prepared. The apparatus which used in measurement system in the first time are the same which used after ten years. The results show that the change of relative humidity value after ten years ranged from $0.1 \%$ to $0.7 \%$. This value is suitable within uncertainty $\pm 2 \%$. The period of stability for each run for all cells was found to be more than five hours and this period enough for calibration. The measurements show that the cells are stable for more than ten years with accepted value.
\end{abstract}

Key words: Saturated salt solutions, stability, relative humidity, dew-point sensor and cells.

\section{Introduction}

National relative humidity scale was established at NIS (National Institute for Standard) using saturated salt solutions cells $[1,2]$. Nine saturated salt solution cells cover a wide relative humidity range from $11 \%$ up to $97 \%$ RH were used for the realization of the scale [3]. Three salts were choice to study time effects which are potassium acetate, potassium carbonate and potassium sulphate. The study was done using three different cells for each salt. The first and second are half and one liter spherical and the third is one liter conical in shape. The comparison between the measurements at first time and second time after ten years for each saturated salt solution was carried out using dew-point meter. The cells was kept in a stable thermostated water bath. The aim of this study is showing the stability of saturated salt solutions cells, which is valid to used in the calibration of relative humidity sensors.

\section{Apparatus}

\subsection{MBW Dew-Point Meter}

The dew point meter MBW DP30, Fig. 1 is for

Corresponding author: Essam Eldin Mahmoud, associated professor, research field: metrology. industrial and laboratory use, for continuous or spot measurement of the dew point of air, gas and gas mixture. It's extended measuring range and its ability to make measurements at high pressures and temperatures enable it to cover a wide range of applications.

The measurement is based on the chilled mirror principle [3], which guarantees direct and accurate measurement of the actual humidity with no errors due to inertia and hysteresis. The mirror status indicator displays the current condition of the dew point mirror. This instrument is available with three stages Peltier cooling, pressure-tight and heated measuring-heads and with stainless steel and Teflon gas circuits for the measurement of corrosive gases. This model includes a built-in gas sampling pump with electronic flow meter) [4].

\subsection{Cell Assembly}

Borosilicate glass is regarding quit suitable for using as a saturated salt solution cells because of its very low probability of chemical reaction [2]. The only disadvantage of using glass is the probability of break due to mechanical shock. The hygrostat shown in Fig. 2a is the half liter spherical shape (cell 1), Fig. $2 b$ is the one liter spherical (cell 2) and Fig. $2 c$ is the 


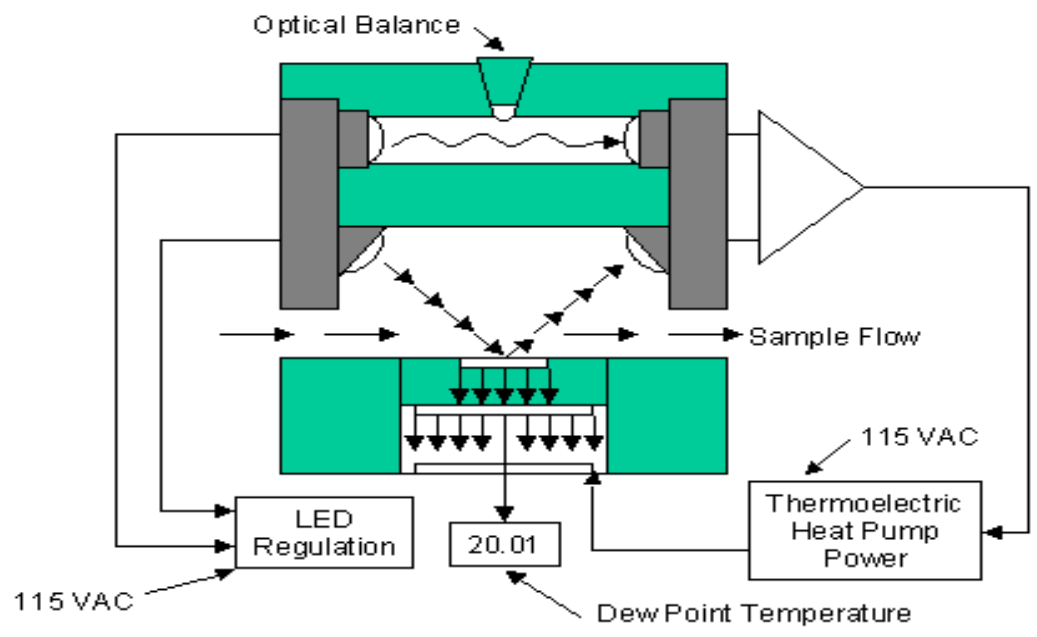

Schematic of conventional chilled mirror sensor.

Fig. 1 Schematic diagram of chilled mirror.

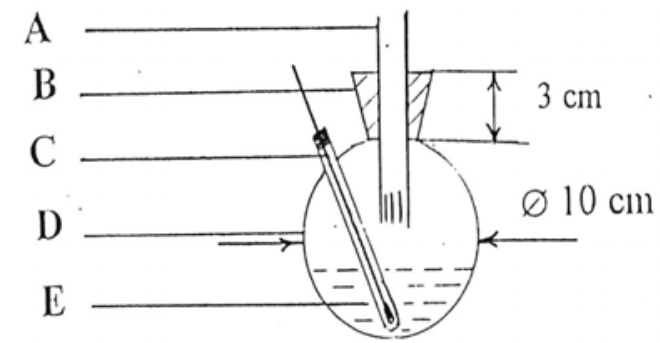

(a)

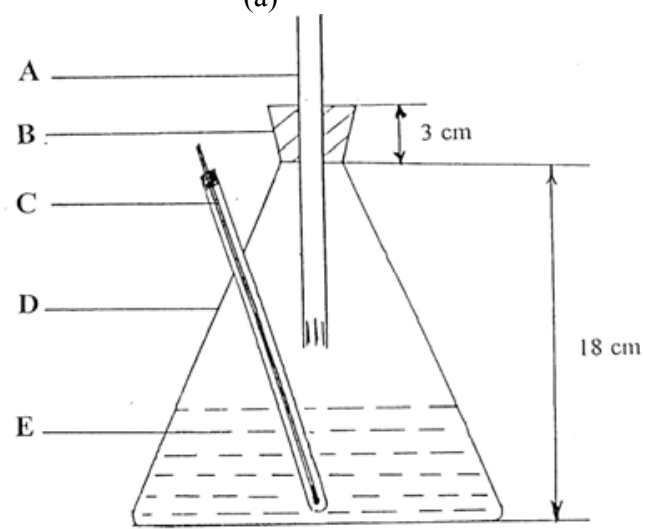

(c)

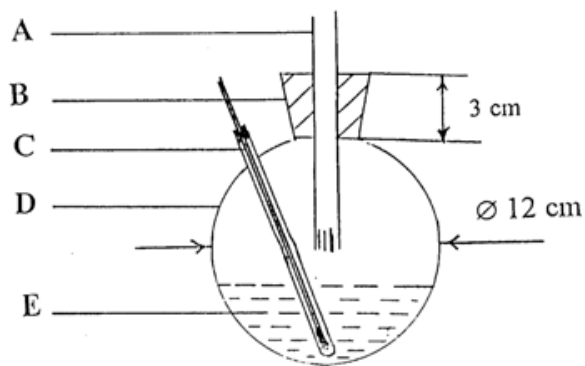

(b)
A: Dew-point meter

B: Feedthrough

C: PT100

D: Hygrostatic

E: Saturated salt solution

Fig. 2 Fig. 2 (a) Hygrostat 1/2 liter spherical shape (cell 1), ( b) Hygrostat 1 liter spherical shape (cell 2) and (c) Hygrostat 1 liter conical shape (cell 3).

one liter conical (cell 3) in shape [1].

\subsection{Water Bath}

The TAMSON model TV-bath are designed to perform a variety of accurate temperature control required for general laboratory use; as a constant temperature bath of about $0.02^{\circ} \mathrm{C}$. The Tamson bath is extremely fitted for temperature control of applications requiring a high degree of stability over a broad temperature range. It is effectively insulated against heat loss by a thick layer of glass wool between inner tank and outer casting, resulting in a relative cool external wall even at high operating temperatures. A circulation pump is built-in for uniform 
Table 1 Comparison between first and second time measurements for three salts with three shapes.

\begin{tabular}{lllllll}
\hline Saturated salt solutions & \multirow{2}{*}{ Literature values (\%) } & \multirow{2}{*}{ Volume (L) } & Shape & $\begin{array}{l}\text { Value } \\
\mathrm{RH}_{1 \mathrm{ft}}\end{array}$ & $\begin{array}{l}\text { Value } \\
\mathrm{RH}_{2 \mathrm{nd}}\end{array}$ & $\begin{array}{l}\text { Difference } \\
\Delta \mathrm{RH}=\mathrm{RH}_{1 \mathrm{ft}}-\mathrm{RH}_{2 \mathrm{nd}}\end{array}$ \\
\hline \multirow{2}{*}{ Potassium acetate } & \multirow{2}{*}{22.5} & $1 / 2$ & Spherical & 22.5 & 22.6 & -0.1 \\
& & 1 & Spherical & 22.8 & 23.4 & -0.6 \\
& & 1 & Conical & 22.6 & 23.3 & -0.7 \\
Potassium iodide & \multirow{2}{*}{68.9} & $1 / 2$ & Spherical & 68.4 & 68.8 & -0.4 \\
& & 1 & Spherical & 68.7 & 68.9 & -0.2 \\
Potassium sulphate & \multirow{2}{*}{97.3} & 1 & Conical & 69.0 & 69.2 & -0.2 \\
& & $1 / 2$ & Spherical & 97.8 & 97.4 & +0.4 \\
& & 1 & Spherical & 97.5 & 97.4 & +0.1 \\
\hline
\end{tabular}

temperature distribution within the bath.

The bath has a built in cooling spiral. The cooled water passing through it was provided from a cooling unit connected to the spiral by thick rubber house. To obtain an even temperature in the bath it was necessary to have no areas where the temperature differs greatly from the rest. Cooling is necessary as the stirring gives off heat due to friction, which causes an increase in temperature of few of tenth of degrees. A flow of cooling water is necessary to compensate for this increase in temperature.

\section{Experimental Method}

The cell was placed in the thermostat water bath whose temperature was adjusted at $25 \pm 0.02{ }^{\circ} \mathrm{C}$ [5]. The temperature of the bath was measured using calibrated RTD (Resistance thermometer detector) previously. A platinum resistance thermometer (pt-100) was used to measure the temperature of the saturated salt solution inside the cell [6]. When the stability of temperature was reached, the measurements were recorded every five minutes using dew-point meter [7]. The relative humidity, the dew points and temperature over saturated salt solution were recorded $[4,8]$.

\section{Results and Discussion}

Three cells of each salts which are potassium acetate $22.5 \%$ RH (Relative humidity), potassium iodide $68.9 \% \mathrm{RH}$ and potassium sulphate $97.3 \% \mathrm{RH}$ were studied, the first is half liter capacity and spherical in shape (cell 1), the second is one liter capacity and spherical in shape (cell 2) and the third is one liter capacity and conical in shape (cell 3). Long-term stability was studied for many runs to comparison between first time and second time measurements. It is clear from Table 1 that measurements of first time is lowest than measurements of second time because potassium acetate is absorbed salt for humidity.

For potassium iodide, it is clear from Table 1 that measurements of first time is lowest than measurements of second time because potassium iodide is absorbed salt for humidity.

For potassium sulphate, it is clear from Table 1 that measurements of first time is highest than measurements of second time because potassium sulphate is rejection salt for humidity.

From Table 1, it is clear that at low relative humidity in potassium acetate $22.5 \%$ minimum difference at half liter spherical and at medium and high relative humidity, minimum difference at one liter conical and spherical. So, the recommendation from this paper that big size cell is more stable per year for medium and high relative humidity, and small size for low relative humidity.

\section{Conclusions}

From study of stability on saturated salt solutions cells after ten years it can conclude that:

(1) The stability of saturated salt solutions after ten years is quit suitable for using up till now;

(2) Renew certifications for saturated salt solutions cells for calibration as a standard; 
(3) New identifications for the cells;

(4) Big size cell is more stable for medium and high relative humidity, and small size for low relative humidity.

\section{References}

[1] Mahmoud, E. E., Halawa, M. M. and El-Sayed, N. I. 2002. "Realization of Humidity Scale Using Saturated Salt Solutions Fixed Point Cells." 4th International Symposium on Humidity and Moisture, Taiwan.

[2] Mahmoud, E. E., Halawa, M. M. and El-Sayed, N. I. 2003. "Study and Characterization of Relative Humidity Fixed Points Cells In The Range From 11\% to 97\%." Ph.D. thesis, Ain Shams university-Cairo-Egypt.

[3] Wiederhold, P. 1997. Water Vapor Measurement.
[4] Essam El-Din Mahmoud Mapan. 2010. "Realization of Relative Humidity Scale From $10 \%$ to $98 \%$ at $25{ }^{\circ}$ C." Journal Metrology Society of India.

[5] OIML R 121, 1996.

[6] Farely, R. and Rotronic, A. G. 2002. "Development of Certified Non-Saturated Salt Humidity Standard 1988-2002." 4th International Symposium on Humidity and Moisture, Taiwan.

[7] Mahmoud, E. E., Halawa, M. M. and ElSayed, N. I. 2002. "Study and Characterization of Relative Humidity Fixed Points Cells in the Range From 11\% to 97\%." The 4th International Symposium on Humidity and Moisture.

[8] Mahmoud, E. E., Halawa, M. M. and ElSayed, N. I. 2002. "Thin Film Capacitive Sensor for Realization of Humidity Scale of National Institute for Standards." Egyptian Society Journal. 